\title{
Pengenalan Teknik Budidaya Kelengkeng Super Sleman Berbasis Lingkungan
}

\author{
Mahfut $^{1^{*}}$ dan Sri Wahyuningsih ${ }^{1}$ \\ ${ }^{1}$ Jurusan Biologi, Fakultas MIPA, Universitas Lampung, Jl. Prof. Dr. Ir. Sumantri Brojonegoro No.1, Gedong \\ Meneng, Rajabasa, Bandar Lampung, Lampung, 35141. \\ *Email korespondensi: mahfutkariem@yahoo.com
}

\begin{abstract}
Abstrak
Perubahan kenaikan temperatur udara sangat dirasakan masyarakat di sekitar Gejayan, Condong Catur, Sleman, Yogyakarta. Penanaman tanaman buah seperti Kelengkeng Super Sleman (KSS) menjadi alternatif dalam memecahkan permasalahan terkait mengurangi dampak pemanasan global melalui program penghijauan. Selain itu memiliki nilai tinggi baik dari sisi pemenuhan gizi maupun produk pemasaran di bidang ekonomi bagi masyarakat sekitar. Pengenalan teknik budidaya KSS berbasis lingkungan di Dusun Gejayan merupakan salah satu bentuk dukungan pembangunan yang berkesinambungan melalui program setiap daerah dalam menghasilkan suatu produk (one village one product). Kegiatan dilakukan melalui tiga tahapan, yaitu; penyuluhan, pelatihan, dan pendampingan secara berkala. Hasil yang diperoleh dalam penyuluhan sebagai kegiatan awal adalah terjadi peningkatan persentase pengetahuan peserta dengan nilai sebelum dan sesudah kegiatan adalah sebesar $69,72 \%$. Hasil juga menunjukkan bahwa warga Padukuhan Gejayan secara umum telah mengalami perubahan paradigma terkait budidaya KSS dan memahami penerapan teknik budidaya KSS berbasis lingkungan. Dampak positif tidak hanya berapa dukungan penghijauan dan pemenuhan gizi warga, tetapi juga menambah perekonomian warga melalui penjualan buah dan bibit ke konsumen. Dengan dukungan penuh dari Kepala Padukuhan Gejayan, penanaman pohon KSS diharapkan terus berkembang dan menjadi suatu budaya di dalam lingkungan Padukuhan Gejayan.
\end{abstract}

Kata Kunci: Kelengkeng, Super Sleman, KSS

\begin{abstract}
Changes in the increase in air temperature are felt by the people around Gejayan, Condong Catur, Sleman, Yogyakarta. Planting fruit trees such as Kelengkeng Super Sleman (KSS) is an alternative in solving related problems reducing the impact of global warming through greening programs. Besides that, it has high values both in terms of fulfilling nutrition and marketing products in the economic field for the surrounding community. The introduction of environmental-based KSS cultivation techniques in Dusun Gejayan is one form of sustainable development support through each region's program in producing a product (one village one product). Activities are carried out through three stages, namely; counseling, training, and assistance on a regular basis. The results obtained in counseling as the initial activity was an increase in the percentage of participants' knowledge with values before and after the activity amounting to $69.72 \%$. The results also show that the residents of Padukuhan Gejayan in general have experienced a paradigm shift related to KSS cultivation and understand the application of environmental-based KSS cultivation techniques. The positive impact is not only how much support for reforestation and fulfillment of nutrition, but also to increase the economy of the citizens through selling fruit and seeds to consumers. With the full support of the Head of Padukuhan Gejayan, planting KSS trees is expected to continue to develop and become a culture within the Padukuhan Gejayan environment.
\end{abstract}

Keywords: Longan Fruit, Super Sleman, KSS

Format Sitasi: Mahfut \& Wahyuningsih, S. (2019). Pengenalan Teknik Budidaya Kelengkeng Super Sleman Berbasis Lingkungan. Jurnal Solma, 8(2), 201-209. Doi: https://dx.doi.org/10.29405/solma.v8i2.3472

Diterima: 12 Juni 2019 | Revisi: 02 Agustus 2019 | Dipublikasikan: 21 Oktober 2019 
(C) 2019. Oleh authors. Lisensi Jurnal Solma, LPPM-Uhamka, Jakarta. Artikel ini bersifat open access yang didistribusikan di bawah syarat dan ketentuan Creative Commons Attribution (CC-BY) license. (http://creativecommons.org/licenses/by/4.0/).

\section{PENDAHULUAN}

Kelengkeng (Dimocarpus longan L.) bukanlah tanaman asli Indonesia, melainkan berasal dari negeri Cina. Kelengkeng di Indonesia terdapat beberapa varietas antara lain: Kelengkeng Lokal, Pingpong, dan Diamond River dari Vietnam, Kelengkeng Itoh dari Thailand dan Malaysia. Di Indonesia, kelengkeng banyak ditemukan di pulau Jawa yang tersebar di beberapa kabupaten, antara lain Ambarawa, Magelang, Temanggung, Wonogiri di Jawa Tengah, dan Tumpang di Jawa Timur (Nakata \& Sugiyama, 2005; Satiadiredja, 1984; Sunanto, 1990; Sunarjono, 2008).

Kelengkeng Super Sleman (KSS) merupakan varietas kelengkeng lokal baru hasil budidaya warga Sleman (Yusuf Sukri Sulaiman, S.I.P) dan Fakultas Biologi Universitas Gadjah Mada baru-baru ini dikembangkan di daerah Sleman dan sekitarnya. Keunggulan buah KSS merupakan varietas yang bisa ditanam di dataran rendah. Kelebihan lain, varietas lokal ini tidak kalah dengan buah kelengkeng Itoh dari Thailand yaitu sama-sama memiliki daging buah yang tebal, biji kecil, dan tidak berair, serta memiliki usia genjah yang lebih pendek, yaitu mampu menghasilkan buah perdana pada usia 2 tahun, 6 bulan lebih cepat daripada buah kelengkeng Itoh (Daryono, Rabbani, \& Purnomo., 2015). Tujuan dari kegiatan ini adalah melakukan sosialisasi, memperkenalkan, dan melakukan pembinaan kelompok petani dan warga Desa Gejayan mengenai aplikasi teknologi tepat guna dalam budidaya KSS di Dusun Gejayan, Sleman.

\section{MASALAH}

Perubahan kondisi udara yang mengalami kenaikan temperatur saat ini sangat dirasakan masyarakat di sekitar Dusun Gejayan, Kecamatan Condong Catur, Kabupaten Sleman, D.I. Yogyakarta, hal tersebut disampaikan oleh Kepala Dusun Gejayan, Bapak H. Nuryanto. Sehingga perlu ditemukannya solusi untuk meminimalisir masalah lingkungan di sekitar dusun tersebut. Penanaman tanaman buah seperti KSS menjadi alternatif dalam memecahkan permasalahan kehidupan terkait dengan keanekaragaman hayati dan mengurangi dampak pemanasan global melalui program penghijauan. Selain itu juga memiliki nilai tinggi baik dari sisi pemenuhan gizi maupun produk pemasaran di bidang 
ekonomi bagi masyarakat sekitar. Pengenalan teknik budidaya KSS berbasis lingkungan di Dusun Gejayan merupakan salah satu bentuk dukungan pembangunan yang berkesinambungan melalui program setiap daerah dalam menghasilkan suatu produk (one village one product) (Kurokawa, Tembo, \& Velde, 2010).

\section{METODE PELAKSANAAN}

Masyarakat di sekitar Dusun Gejayan kini selalu merasakan panas dengan temperatur udara yang tinggi hingga tidak dapat merasakan kondisi udara yang dingin seperti di lereng gunung pada masa lampau. Masalah yang ingin dipecahkan dalam kegiatan ini adalah bagaimana mengurangi dampak pemanasan global dengan penghijauan serta peningkatan kehidupan terkait dengan produksi tanaman pangan yang lebih bermutu melalui aplikasi bioteknologi.

Metode pelaksanaan kegiatan dibagi menjadi 3 tahap yaitu: Penyuluhan, Pelatihan, dan Pendampingan, yang dilakukan secara berkala. Skema kerangka pemecahan masalah disusun berdasarkan pernyataan (Hanafi, 1986; Samsudin, 1977) bahwa penyuluhan merupakan tahap awal salah satu jembatan antara masyarakat dan penemu teknologi baru. Teknik pengumpulan data dilakukan dengan teknik kuisioner melalui pre-tes dan post-tes pada saat sebelum dan setelah kegiatan. Data langsung dianalisis untuk mengetahui persentase peningkatan pengetahuan peserta kegiatan. Kegiatan Pengabdian Kepada Masyarakat ini dilakukan selama 4 bulan, pada Juli - Oktober 2016. Khalayak sasaran utama adalah masyarakat dari Kelompok Tani Sleman di Dusun Gejayan, Kelurahan Condong Catur, Kabupaten Sleman, D.I. Yogyakarta.

\section{PEMBAHASAN}

\section{Penyuluhan}

Kegiatan penyuluhan dilaksanakan pada hari Sabtu, tanggal 6 Agustus 2016 di balai Padukuhan Gejayan. Kegiatan penyuluhan ini dihadiri oleh peserta 22 warga. Acara penyuluhan di buka dengan sambutan Kepala Padukuhan Gejayan, H. Nuryanto yang dilanjutkan dengan pemberian materi teknik budidaya KSS oleh tim PKM. Selama penyampaian materi dilakukan juga diskusi dan tanya jawab secara interaktif dengan tim PKM dan Ketua Kelompok Tani KSS, Yusuf Sukri sulaiman, S.I.P. Acara selanjutnya adalah kunjungan ke lapangan tim PKM dan peserta penyuluhan ke lokasi 
pusat pembudidayaan KSS di depan rumah Kepala Padukuhan Gejayan dan Ketua Kelompok Tani Padukuhan Gejayan.

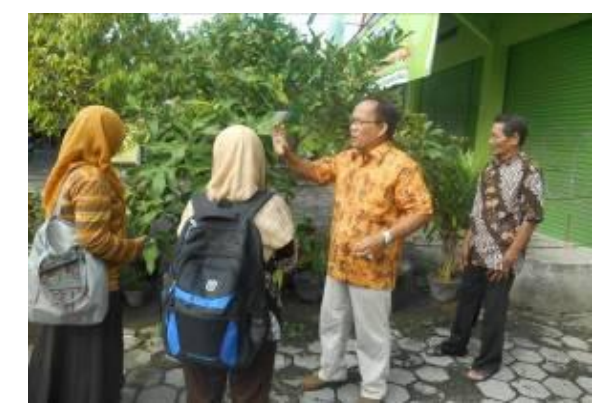

Gambar 1. Kunjungan ke lokasi pusat pembudidayaan KSS

Hasil sementara mengenai pengetahuan yang diperoleh peserta diketahui melalui evaluasi terhadap peserta pelatihan. Evaluasi bertujuan untuk mengumpulkan data baik pada saat proses sampai hasil yang telah dicapai melalui kegiatan pelatihan. Evaluasi ini untuk mendapatkan masukan yang dapat dijadikan dasar untuk kegiatan lanjutan yang akan dilaksanakan. Evaluasi dalam kegiatan ini dilakukan dalam tiga tahap, yaitu di awal melalui pre-tes, pada saat proses ceramah melalui diskusi dan tanya jawab, serta diakhir kegiatan melalui post-tes (Hanafi, 1986; Samsudin, 1977).

Secara umum peserta pelatihan banyak yang mengetahui tentang teknik budadaya tanaman buah yaitu kelengkeng. Berdasarkan data hasil evaluasi yang diperoleh pada Tabel 1 diketahui bahwa terjadi peningkatan pengetahuan dan pemahaman peserta pelatihan mengenai budidaya KSS berbasis lingkungan sebesar 69,72\%. Harapannya adalah pengetahuan yang diperoleh selama pelatihan dapat diterapkan dalam kehidupan sehari-hari serta menularkannya kepada masyarakat luas di Kelurahan Gejayan, Condong Catur, Sleman. (Hanafi, 1986) menjelaskan peningkatan pengetahuan tersebut menunjukkan keberhasilan proses adopsi inovasi teknologi baru melalui kegiatan penyuluhan yang mencakup tahapan sadar (awareness), minat (interest), dan penilaian (evaluation).

Tabel 1. Hasil Pre-tes dan Post-tes serta persentase peningkatan pengetahuan peserta pelatihan

\begin{tabular}{ccccc}
\hline Peserta & Pre-tes & Post-tes & Peningkatan Nilai (Poin) & Persentase Peningkatan (\%) \\
\hline A & 60 & 100 & 40 & 66.67 \\
B & 60 & 100 & 40 & 66.67 \\
C & 70 & 100 & 30 & 42.86 \\
D & 50 & 100 & 50 & 100 \\
E & 50 & 100 & 50 & 100 \\
F & 40 & 100 & 60 & 150
\end{tabular}




\begin{tabular}{ccccc} 
G & 90 & 100 & 10 & 11,11 \\
$\mathrm{H}$ & 60 & 100 & 40 & 66.67 \\
$\mathrm{I}$ & 50 & 100 & 50 & 100 \\
$\mathrm{~J}$ & 60 & 100 & 40 & 66.67 \\
$\mathrm{~K}$ & 60 & 100 & 40 & 66.67 \\
$\mathrm{~L}$ & 70 & 100 & 30 & 42.86 \\
$\mathrm{M}$ & 80 & 100 & 20 & 25 \\
$\mathrm{~N}$ & 70 & 100 & 30 & 42.86 \\
$\mathrm{O}$ & 70 & 100 & 30 & 42.86 \\
$\mathrm{P}$ & 60 & 100 & 40 & 66.67 \\
$\mathrm{Q}$ & 50 & 100 & 50 & 100 \\
$\mathrm{R}$ & 50 & 100 & 50 & 100 \\
$\mathrm{~S}$ & 70 & 100 & 30 & 42.86 \\
$\mathrm{~T}$ & 50 & 100 & 50 & 100 \\
$\mathrm{U}$ & 60 & 100 & 40 & 66.67 \\
$\mathrm{~V}$ & 60 & 100 & 40 & 66.67 \\
Rerata & 60,90 & 100 & 39,09 & 69,72 \\
\hline
\end{tabular}

\section{Pelatihan}

Tahap pelatihan dilakukan pada hari Sabtu, 20 Agustus 2016, dengan kegiatan yang meliputi pengenalan cara budidaya KSS yang berlokasi di rumah salah satu warga yaitu Ketua Kelompok Tani Padukuhan Gejayan, Yusuf Sukri Sulaiman S.I.P. (Gambar 2). Pelatihan ini bertujuan agar Kelompok Tani Gejayan memiliki kemandirian dalam budidaya KSS hingga mampu memproduksi buah yang berkualitas. Pelatihan penanaman dan perawatan KSS diawali dengan teknik perawatan dalam pot teknik aplikasi hormon untuk teknik pembungaan dan pembuahan, perawatan buah dan panen, serta teknik pengemasan bibit (Prawitasari, 2002; Tyas, 2013; Usman, 2004; Yulianto, Susilo, \& Juanda, 2008). Pelatihan ini merupakan keberhasilan proses adopsi inovasi teknologi baru yang mencakup tahapan sadar (awareness), minat (interest), penilaian (evaluation), dan percobaan (trial) (Hanafi, 1986).
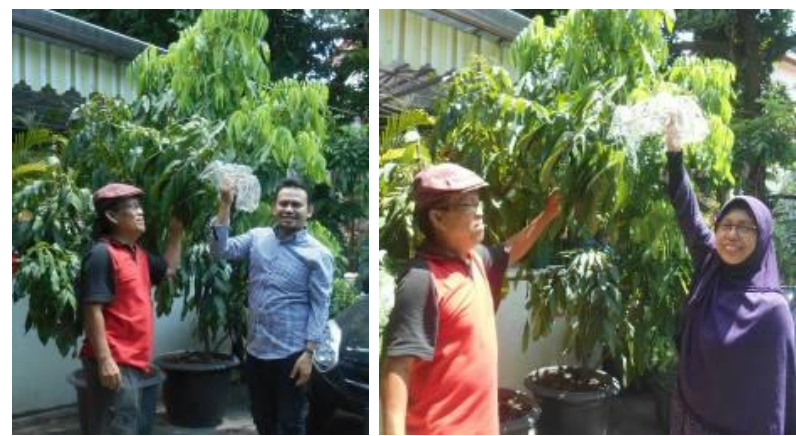

Gambar 2. Tim PKM pada pelatihan budidaya KSS

\section{Teknik perawatan dalam pot}


Perawatan di dalam pot besar meliputi pencabutan gulma, penyiraman pada pagi hari, pukul 06.00 dan pada sore hari pukul 16.00 waktu setempat, pemupukan satu minggu sekali. Dalam teknik perawatan, metode penyiraman dilakukan secara terintegrasi sehingga mempermudah proses penyiraman pot.

\section{Teknik aplikasi hormon untuk teknik pembungaan dan pembuahan}

Pohon KSS didalam pot yang kurang lebih berusia 1 tahun 7 bulan dengan keliling batang berukuran kurang lebih $5 \mathrm{~cm}$ sudah mampu dibungakan melalui aplikasi pupuk Nongfeng yang terdiri dari 3 jenis yaitu pupuk pengembang akar, daun, bunga (Gambar 3). Bunga akan bermunculan 45 hari pasca aplikasi hormon.
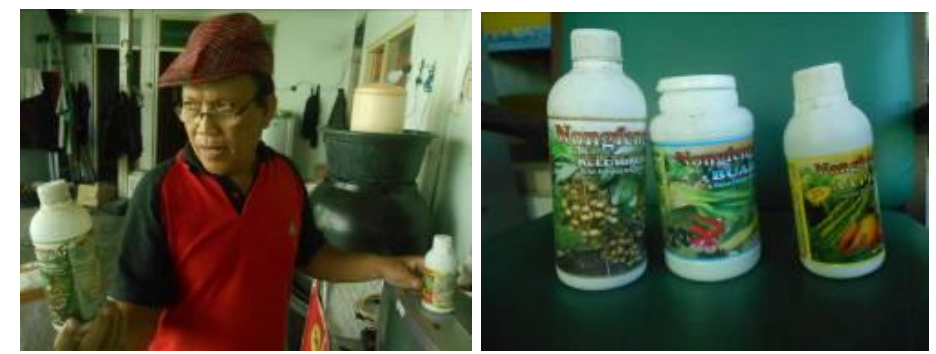

Gambar 3. Aplikasi variasi jenis pupuk Nongfeng yang digunakan dalam budidaya KSS

\section{Perawatan buah dan panen}

Buah yang terbentuk setelah proses penyerbukan membutuhkan perawatan sampai dengan siap panen, yaitu selama 150 hari. Pemasangan kreneng/ jaring pada buah ini bertujuan untuk menghindari serangan hewan pemakan buah (kelelawar dan burung). Panen dilakukan saat buah sudah mengalami fase penebalan daging buah dan ditandai warna biji yang sudah coklat serta tekstur kulit buah berwarna coklat tua dan halus.

Gambar 4. Pemasangan kreneng/ jaring kasa jala pada buah

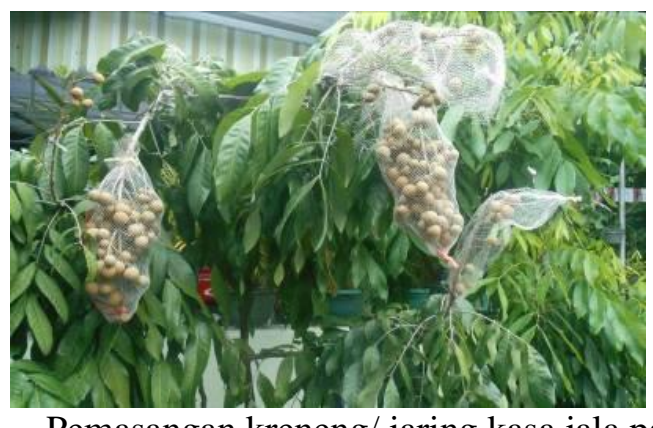

\section{Teknik pengemasan bibit KSS}

KSS sangat diminati konsumen baik dari daerah D.I. Yogyakarta sendiri maupun luar kota. Pada tahap ini juga diperkenalkan cara pengemasan bibit kelengkeng untuk dikirimkan ke luar kota menggunakan jasa pengiriman barang (Gambar 5). 


\section{Gambar 5.
3. Pendampingan}
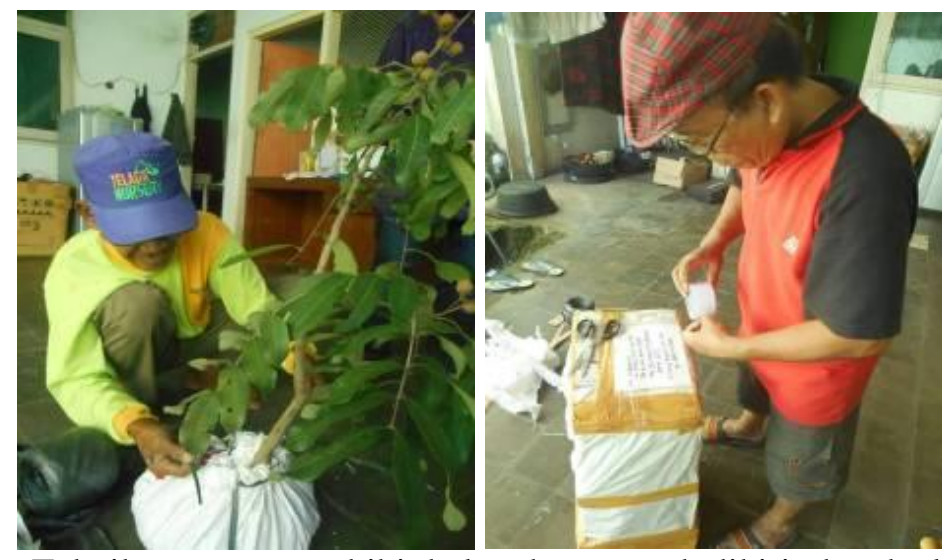

Proses pendampingan dilakukan pada hari Sabtu, 1 Oktober 2016 (Gambar 6) dan juga dilakukan sepanjang proses perawatan bibit KSS. Warga dapat berkonsultasi langsung dengan Ketua Kelompok Tani KSS, Bapak Yusuf Sukri Sulaiman, S.I.P. Selama pelaksanaan kegiatan dilakukan juga pembekalan, monitoring, dan sekaligus evaluasi keberhasilan kegiatan PKM kepada perwakilan Kelompok Tani Gejayan.
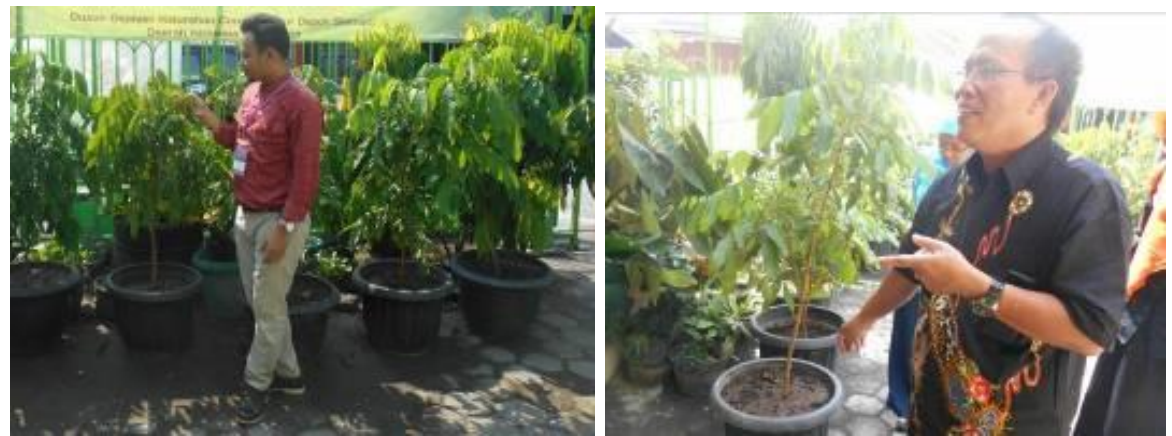

Gambar 6. Kegiatan pendampingan dan evaluasi budidaya KSS

Di dalam tahap kegiatan pendampingan dan evaluasi ini, dapat dilihat hasil kegiatan transfer ilmu kegiatan penyuluhan dan pelatihan yang telah dilakukan sebelumnya (Hanafi, 1986; Samsudin, 1977). Pada kegiatan ini telah mencakup seluruh tahapan keberhasilan proses adopsi inovasi teknologi baru yang meliputi tahapan sadar (awareness), minat (interest), penilaian (evaluation), percobaan (trial), dan penerimaan (adopstion) (Hanafi, 1986).

Hasil yang diperoleh adalah beberapa tanaman telah muncul bunga dan buah setelah aplikasi hormon dengan berbagai jenis pupuk Nongfeng, serta terdapat beberapa tanaman 
yang sudah menghasilkan buah masak yang bisa dinikmati. Selain itu pengembangan bibit juga aktif dilakukan oleh Kelompok Tani KSS, sehingga anggota kelompok tani sudah dapat menikmati budidaya KSS melalui penjualan bibit ke konsumen baik dari D.I.Yogyakarta sendiri maupun luar kota.

\section{KESIMPULAN}

Teknik budidaya Kelengkeng Super Sleman berbasis lingkungan telah dipahami dan diterapkan oleh warga Padukuhan Gejayan. Dampak positif tidak hanya berapa dukungan penghijauan dan sebagai alternatif untuk meningkatkan pemenuhan gizi warga, tetapi juga menambah perekonomian warga. Produk kegiatan ini meliputi program penghijauan, buah, dan bibit KSS.

\section{UCAPAN TERIMA KASIH}

Pengabdian ini dibiayai oleh DIPA BLU Universitas Lampung, melalui Surat Keputusan Penetapan Pemenang Hibah Pengabdian Kepada Masyarakat DIPA BLU Universitas Lampung Tahun 2016 Nomor 733/UN26/PM/2016, tanggal 20 Juni 2016.

\section{DAFTAR PUSTAKA}

Daryono, B. S., Rabbani, A., \& Purnomo. (2015). Aplikasi Teknologi Budidaya Kelengkeng Super Sleman di Padukuhan Gejayan. Bioedukasi, 9(1), 57-61.

Hanafi, A. (1986). Memasyarakatkan Ide-Ide baru. Surabaya: Usaha Nasional.

Kurokawa, K., Tembo, F., \& Velde, D. W. (2010). Challenge for The OVOP Movement in Sub-Saharan Africa: Insight from Malawi, Japan and Thailand. Tokyo: Japan International Cooperation Agency esearch Institute.

Nakata, M., \& Sugiyama. (2005). Morphological Study of The Structure and Development of Longan Inflorensence. Jurnal Amer Horticulture, 130(6), 793-797.

Prawitasari, T. (2002). Perkembangan Struktur Meristem Reproduktif pada Proses Pembungaan Tanaman Lengkeng. Jurnal Hayati, 9(4), 119-124.

Samsudin, U. (1977). Dasar-Dasar Penyuluhan dan Modernisasi Pertanian. Bandung: Bina Cipta.

Satiadiredja, S. (1984). Holtikultura Pekarangan dan Buah-buahan. Jakarta: CV. Yasaguna.

Sunanto, H. (1990). Budidaya Lengkeng dan Aspek Ekonominya. Yogyakarta: Kasinius.

Sunarjono, H. (2008). Berkebun 21 Jenis Tanaman Buah. Jakarta: Swadaya.

Tyas, P. . (2013). Perkembangan Pembungaan Lengkeng (Dimocarpus longan Lour) 
'Diamond River.' Universitas Jember.

Usman, B. (2004). Sukses Membuahkan Lengkeng dalam Pot. Jakarta Selatan: PT. Agromedia Pustaka.

Yulianto, J., Susilo, D., \& Juanda. (2008). Keefektifan Teknik Perangsangan Pembungaan Pada Kelengkeng. Jurnal Hortikultura, 18(2), 148-154. 